\title{
Rótulos de alimentos: revisão de literatura no contexto da promoção da saúde e alimentação adequada e saudável
}

\author{
Food labels: review of literature in the context of the promotion of health \\ and adequate and healthy food
}

Mônica Cecília Santana Pereira ${ }^{1}$, Maria de Fátima Lobato Tavares ${ }^{2}$, Lilian Cristina Gomes do Nascimento ${ }^{1}$, Maria Georgina Marques Tonello ${ }^{1}$, Renata Romanholi Pinhati $^{3}$, Maria da Penha Henriques do Amaral $^{3}$, Helena Siqueira Vassimon ${ }^{1}$

${ }^{1}$ Universidade de Franca (UNIFRAN)

${ }^{2}$ Fundação Oswaldo Cruz

${ }^{3}$ Universidade Federal de Juiz de Fora (UFJF)

\section{Resumo}

Introdução: Diante do cenário desafiador de enfrentamento de doenças crônicas não transmissíveis (DCNT), os rótulos de alimentos deveriam ser ferramentas para escolhas de alimentos saudáveis. $\mathrm{O}$ Brasil possui trajetória de referência na área de regulamentações e de ações voltadas para promover a alimentação adequada e saudável dentro do contexto da promoção de saúde e o assunto "rótulos de alimentos" merece destaque. Objetivo: Este artigo teve como objetivo realizar uma revisão bibliográfica sobre rótulos de alimentos no Brasil, no contexto da promoção de saúde e promoção da alimentação adequada e saudável. Metodologia: A metodologia utilizada foi a revisão narrativa de artigos publicados em periódicos científicos e literatura cinzenta no Brasil. Resultados/Discussão: Mesmo com os avanços normativos, os rótulos, ainda, apresentam informações muito técnicas, além de serem utilizados com frequência como peças publicitárias que induzem o consumidor a interpretações equivocadas. Conclusão: Por meio deste estudo, é possível reforçar a importância do uso dos rótulos nas escolhas alimentares adequadas e saudáveis no contexto da promoção da saúde no Brasil. Fica evidente a necessidade de uma maior inserção dos rótulos nas iniciativas de educação alimentar e nutricional com o intuito de empoderar o consumidor e fortalecer sua autonomia para efetuar suas escolhas alimentares.

Palavras-chave: Rótulos de alimentos; Promoção da saúde; Doenças crônicas não transmissíveis

Autor correspondente:

M.C.S. PEREIRA

Endereço: Rua Capitão Arnaldo de Carvalho, $n^{\circ} 569$, Apt.: 203 , Jardim

Glória - Juiz de Fora/MG CEP: 36036-180

Recebido em: 03/09/2016

E-mail: monicasantanapereira@bol.com.br 


\section{Abstract}

Introduction: Faced with the challenging scenario of coping with chronic noncommunicable diseases (CDNT), food labels should be a tools for healthy food choices. Brazil has reference trajectory in the area of regulations and actions aimed to promote adequate and healthy food within the context of health promotion and the subject "food labels" deserves attention. Objective: This article aimed to carry out a bibliographic review of food labels in Brazil in the context of health promotion and promotion of adequate and healthy food. Methodology: The methodology used was the narrative review of articles published in scientific journals and gray literature in Brazil. Results / discussion: Even with the normative advances, the labels still present very technical information, besides being frequently used as advertising pieces, inducing the consumer to misinterpretations. Conclusion: Through this study, it is possible to reinforce the importance of the use of labels in appropriate and healthy food choices in the context of health promotion in Brazil. There is a clear need for greater label insertion in food and nutrition education initiatives with the aim of empowering the consumer and strengthening their autonomy to make their food choices.

Key-words: Food labels; Health promotion; Chronic non-communicable diseases.

\section{Introdução}

Com as mudanças econômicas, políticas, sociais e culturais iniciadas no século XIX e intensificadas no século passado, as políticas de saúde com a crise do Estado de Bem-Estar Social passaram a ser alvo de muitas críticas e de muitas reflexões em vários países. As mudanças no perfil epidemiológico exigiram uma reorientação dos serviços de saúde, visto que as doenças crônicas não transmissíveis (DCNTs) tornaram-se mais prevalentes e demandam altos investimentos em saúde ${ }^{1,2,3}$.

Assim, no início da década de 70, ganha força no contexto internacional a Promoção da Saúde (PS). Surge, à época, como uma estratégia promissora para o enfrentamento global dos diversos problemas de saúde que afetavam a população ${ }^{4}$. Pode-se dizer que a PS teve início no Canadá, com a divulgação do Informe Lalonde (1974), relatório apresentado pelo então ministro da saúde do Canadá. Esse documento tem sua importância histórica, uma vez que foi capaz de retratar na época a correlação entre saúde, desenvolvimento econômico e justiça social, e considerado por alguns autores como marco de inserção da promoção da saúde no contexto políticoestratégico ${ }^{5}$.

A chegada do movimento de PS, no Brasil, coincide com o período da luta pela redemocratização. No mesmo ano da $1^{\mathrm{a}}$ Conferência Internacional sobre Promoção da Saúde (CIPS), que aconteceu em 1986, na cidade de Ottawa, ocorria, simultaneamente, no Brasil, a $8^{\text {a }}$ Conferência Nacional de Saúde, que, mais tarde, receberia a denominação de Movimento de Reforma Sanitária. Como fruto da $1^{\text {a }}$ CIPS tem-se a Carta de Ottawa, considerada referencial teórico e peça basilar no desenvolvimento do conceito de $\mathrm{PS}^{6,7}$. A Carta de Ottawa ${ }^{8}$ define PS como "processo de capacitação da comunidade para atuar na melhoria de sua qualidade de vida e saúde, incluindo uma maior participação no controle deste processo".

Nas últimas décadas, a PS vislumbra um cenário desafiador, constituído por uma composição social resultante do crescimento da urbanização, da industrialização e do aumento do número de mulheres no mercado de trabalho. Seguindo a tendência mundial, o Brasil vivencia um momento de transição demográfico-epidemiológica, proveniente de mudanças socioeconômicas que refletem, diretamente, na transformação do perfil de saúde da população ${ }^{9}$. As implicações, trazidas por este novo cenário, podem ser traduzidas em aumento do sedentarismo, das dietas hipercalóricas, da obesidade e das DCNTs ${ }^{9 ; 10}$.

Segundo a Organização Mundial de Saúde (OMS), as DCNTs são as principais causas de mortes no mundo, respondem por $63 \%$ dos óbitos, e seu maior número refere-se às doenças cardiovasculares. No Brasil, o quadro não é diferente da realidade mundial, as DCNTs constituem o problema de saúde de maior magnitude, somente em 2009, corresponderam a $72,4 \%$ dos casos de morte no país ${ }^{10,11}$.

Entre os determinantes sociais das DCNTs apontados no Plano de Ações Estratégicas para o Enfrentamento das Doenças Crônicas não Transmissíveis no Brasil, 2011-2022, do Ministério 
da Saúde ${ }^{12}$ encontra-se a alimentação inadequada. A associação indesejada de alimentação inadequada e de reduzida prática de atividade física descortina um cenário de sobrepeso e de obesidade. Os dados do Vigitel 2014 (Vigilância de Fatores de Risco e Proteção para Doenças Crônicas por Inquérito Telefônico) ${ }^{13}$ mostram uma frequência de excesso de peso de $52,5 \%$, maior nos homens $(56,5 \%)$ do que nas mulheres $(49,1 \%)$. Uma avaliação, publicada em 2014, por Malta \& Júnior ${ }^{14}$, apresenta os avanços obtidos nos três anos de implantação do Plano de Enfrentamento das DCNTs e evidencia que a obesidade em adultos foi a única que não conseguiu alcançar resultados significativos, de 15,1\% em 2010 passou para 17,5\% em 2013.

Para atender ao novo perfil de alimentação da população, a indústria de alimentos acelerou seu crescimento, conseguiu ofertar inovações aos consumidores em curto período de tempo. Como consequência, as pesquisas e os inquéritos retratam que, nos últimos anos, ocorreu um aumento no consumo de alimentos de origem animal, refrigerantes, fast foods, enlatados, congelados $\mathrm{e}$ alimentos pré-cozidos que, somados aos apelos do marketing, contribuíram para o desenvolvimento de hábitos não saudáveis como, por exemplo, substituir as refeições por lanches, devido à praticidade ${ }^{15}$.

A alimentação, para muitas pessoas, perdeu espaço como fonte de identidade cultural e familiar, de prazer e de saúde, em razão do pouco tempo que a vida moderna acelerada concede ao indivíduo. Toda essa "modernidade alimentar" culminou na redução da qualidade da alimentação (alto consumo de produtos processados e ultraprocessados com baixo valor nutritivo) e, no avanço assustador da obesidade, um sério problema de saúde pública, com prevalência alarmante em níveis epidêmicos ${ }^{16,17}$.

A rotulagem dos alimentos é um canal de comunicação fundamental para auxiliar o consumidor a realizar suas escolhas alimentares de forma consciente. No entanto, as informações disponibilizadas, nesse canal, são, geralmente, difíceis de serem decodificadas e interpretadas pelos consumidores. Fato que pode impactar, diretamente, em escolhas alimentares inadequadas, reforçadas, muitas vezes, pelo uso das estratégias de marketing persuasivas e enganosas ${ }^{18}$. Ações coordenadas entre o governo, a sociedade civil organizada, as instituições públicas e/ou privadas e a academia favorecem o desenvolvimento de estratégias concretas que efetivem a rotulagem como um canal de comunicação que garanta ao consumidor o direito à informação completa e verdadeira ${ }^{19}$.

Ao observar a necessidade de abordar a temática de rótulos de alimentos do ponto de vista da promoção da saúde e alimentação adequada e saudável, o presente artigo tem como objetivo realizar uma revisão narrativa sobre essa temática.

\section{Metodologia}

Para atingir os objetivos propostos neste trabalho, foi realizada uma revisão narrativa. As revisões consideradas narrativas, são aquelas em que a eleição dos trabalhos, bem como a interpretação destes, podem estar sujeitas à subjetividade dos autores. Na revisão narrativa, o intuito da busca não é esgotar as fontes de informações, e sim, encontrar uma fundamentação teórica adequada ao tema estudado ${ }^{20}$.

Para a redação da revisão bibliográfica, foi realizada a busca por artigos científicos disponíveis nas bases de dados do Portal de Periódicos Capes, Scielo e Google Acadêmico. Também foram consideradas literaturas cinzentas relacionadas ao tema, entendida aqui como um tipo de informação produzida fora dos canais de publicação e distribuição acadêmicos, que foca a literatura não convencional, conhecida como literatura informal ou invisível, a qual inclui, por exemplo, relatórios técnicos e de pesquisa elaborados (para circulação interna ou restrita), as comunicações apresentadas em eventos, os anais e atas de reuniões, legislações e documentos oficiais governamentais $^{21}$.

A revisão aborda as políticas públicas vinculadas à alimentação e à saúde; a importância de uma rotulagem de fácil compreensão para alimentação saudável e adequada; a rotulagem como meio de comunicação, educação e promoção da saúde e por último aborda o marketing da indústria alimentícia e a necessidade do apoio político e social na busca de ações concretas para frear as informações abusivas e enganosas que ludibriam o consumidor.

\section{Resultado e discussão}

\section{Políticas de alimentação e de saúde}

Para se alcançar um padrão de alimentação saudável e adequada, conforme priorizam a Política Nacional de Promoção da Saúde (PNPS), a Política Nacional de Alimentação e Nutrição (PNAN) e a Lei Orgânica de Segurança Alimentar e Nutricional (LOSAN) - Lei Federal no ${ }^{\circ} 11.346 / 2006$, é necessário percorrer os caminhos da segurança alimentar e nutricional $(\mathrm{SAN})^{22,23}$.

A SAN ganhou o devido reconhecimento pelo Estado como objeto de política pública por intermédio da LOSAN, que criou o Sistema Nacional de Segurança Alimentar e Nutricional (SISAN), tido por muitos militantes como marco regulatório no direito à alimentação, considerado fruto proveniente do intenso debate entre a sociedade civil e o governo ${ }^{22,23}$.

Com base nos artigos da LOSAN infracitados, pode-se constatar que as medidas relacionadas à segurança alimentar e nutricional, devem ser coordenadas e integradas com o propósito de garantir não apenas que se faça valer o direito do cidadão ao 
acesso à alimentação, mas que essa seja regular, adequada e de qualidade sem comprometer o acesso a outras necessidades ${ }^{22}$.

Art. $2^{o}$ A alimentação adequada é direito fundamental do ser humano, inerente à dignidade da pessoa humana e indispensável à realização dos direitos consagrados na Constituição Federal, devendo o poder público adotar as políticas $e$ ações que se façam necessárias para promover e garantir a segurança alimentar e nutricional da população.

Art. $3^{\circ}$ A segurança alimentar e nutricional consiste na realização do direito de todos ao acesso regular e permanente a alimentos de qualidade, em quantidade suficiente, sem comprometer o acesso a outras necessidades essenciais, tendo como base práticas alimentares promotoras de saúde que respeitem a diversidade cultural e que sejam ambiental, cultural, econômica e socialmente sustentáveis”.

O cidadão-consumidor tem assegurados os direitos à saúde, à segurança alimentar e nutricional bem como à informação completa e verdadeira, resguardados pela Constituição Federal e pelas respectivas leis: Lei no 8080/1990 - Lei Orgânica da Saúde (criou o SUS), Lei n ${ }^{\circ} 11.346 / 2006$ - Lei Orgânica da SAN (criou o SISAN) e Lei no 8078/1990 - (criou o Código de Defesa do Consumidor CDC $)^{22,24,25}$.

Dentre as numerosas atuações definidas na Lei Orgânica da Saúde (LOS), que visa à redução de riscos de doenças e de outros agravos, encontra-se a execução de ações de Vigilância Sanitária (VISA), que objetivam garantir a qualidade dos alimentos por meio da fiscalização e da inspeção de alimentos, águas e bebidas para o consumo humano ${ }^{24}$. A VISA, em todas as suas esferas de atuação, federal, estadual e municipal, é responsável por fazer cumprir a regulamentação sanitária vigente, valendo-se do poder de polícia atribuído aos fiscais sanitários. As ações das VISAs são imprescindíveis para evitar que o consumidor seja ludibriado com informações enganosas presentes nos alimentos disponibilizados para consumo no comércio. No campo da alimentação, é por meio de órgãos de fiscalização como VISAs, Ministério da Agricultura Pecuária e Abastecimento (MAPA), Órgão de Proteção e Defesa do Consumidor (PROCON), Instituto Nacional de Metrologia, Qualidade e Tecnologia (INMETRO) e Ministério Público que o Estado exerce seu dever de prevenir riscos, promover saúde, coibir irregularidades, ampliar ações educativas, garantir o acesso à informação ${ }^{27}$.

Ao avaliar as disposições, os princípios, os objetivos e as diretrizes da PNPS, da PNAN, da LOS e da LOSAN no que se refere ao direito humano à alimentação, é possível verificar que primam por ações intersetoriais e pela participação social. Todas corroboram com a importância da intersetorialidade, nos setores trabalha-se de forma interligada e articulada o que contribui para a potencialização das ações. Com as ações intersetoriais, é possível viabilizar que os diversos setores públicos dialoguem entre si e com os setores privados e a sociedade civil $^{1,22,24,26}$.

Estabelecido o diálogo, torna-se real e factível a superação da cultura administrativa fragmentada que dispõe de informações e de conhecimentos pulverizados, evitam-se desperdícios de recursos públicos, reduz a superposição das ações e, consequentemente, aumenta a eficiência e a efetividade das políticas frente aos condicionantes e determinantes sociais. Em relação à defesa pela participação social, as políticas primam pelo fortalecimento da autonomia dos indivíduos em sua capacidade de escolhas, e contribuem para a formação de cidadãos mais críticos e mais conscientes ${ }^{21,22,24,26}$.

\section{Rótulos de alimentos: foco no consumidor}

A busca por uma alimentação saudável e segura perpassa pelos rótulos regularizados, que são instrumentos capazes de empoderar o consumidor e resguardá-lo de possíveis danos à saúde. A rotulagem dos alimentos constitui instrumento central no aperfeiçoamento do direito à informação. $\mathrm{O}$ acesso à informação fortalece a capacidade de análise e de decisão do consumidor; portanto, essa ferramenta deve ser clara e precisa para que possa auxiliar na escolha de alimentos mais saudáveis e seguros ${ }^{26}$. Mesmo com o avanço normativo, ainda é possível se deparar com rótulos que contêm informações, excessivamente, técnicas e publicitárias, o que induz a interpretações equivocadas $^{28}$.

O Plano de Ações para a Estratégia Global de Prevenção e Controle das Doenças Crônicas Não Transmissíveis 2013-2020 da Organização Mundial de Saúde assegura que com o apoio dos atores sociais e do governo, ao promover incentivos e parcerias, é possível colocar em prática as mais variadas ações (regulatórias ou não) em favor de uma alimentação saudável ${ }^{29}$.

Ações políticas para a promoção de alimentação saudável foram compiladas e definidas pelo World Cancer Research Fund International (Fundo Internacional de Pesquisa do Câncer) no quadro denominado de NOURISHING (Quadro 1) ${ }^{30,31}$. O quadro apresenta dez grandes áreas estratégicas de ação que adaptadas à realidade de cada local propiciam uma alimentação saudável. A rotulagem de alimentos ocupa lugar prioritário no domínio "Ambiente e Alimentação"30. 
Quadro1: Ações para a promoção da alimentação saudável

\begin{tabular}{|c|c|c|c|}
\hline Domínio & $\mathbf{N}$ & Área política & Exemplos de potenciais ações políticas \\
\hline \multirow[t]{6}{*}{$\begin{array}{l}\text { Ambiente e } \\
\text { Alimentação }\end{array}$} & & $\begin{array}{l}\text { Padrões de rotulagem } \\
\text { nutricional e regulamentação no } \\
\text { uso de alegações e alegações } \\
\text { implícitas nos alimentos. }\end{array}$ & $\begin{array}{l}\text { Listas de nutrientes nas embalagens de alimentos } \\
\text { claramente visíveis e de fácil interpretação; e rótulos } \\
\text { com a descrição das calorias; identificação nas } \\
\text { prateleiras; normas sobre as alegações nutricionais e } \\
\text { de saúde. }\end{array}$ \\
\hline & $\mathbf{O}$ & $\begin{array}{l}\text { Oferecer alimentos saudáveis e } \\
\text { estabelecer padrões em } \\
\text { instituições públicas ou outros } \\
\text { locais específicos. }\end{array}$ & $\begin{array}{l}\text { Programas de frutas e de vegetais, padrões de } \\
\text { educação no trabalho. }\end{array}$ \\
\hline & $\mathbf{U}$ & $\begin{array}{l}\text { Usar ferramentas econômicas } \\
\text { para incentivar o acesso à } \\
\text { aquisição de alimentos. }\end{array}$ & $\begin{array}{l}\text { Subsídios direcionados a promoções de preços no } \\
\text { ponto de venda; preço por unidade; impostos para } \\
\text { alimentos relacionados com a saúde. }\end{array}$ \\
\hline & $\mathbf{R}$ & $\begin{array}{l}\text { Restringir a publicidade de } \\
\text { alimentos e de outras formas de } \\
\text { promoção comercial. }\end{array}$ & $\begin{array}{l}\text { Restringir a publicidade direcionada a crianças que } \\
\text { incentive dietas pouco saudáveis em todas as formas } \\
\text { de meios de comunicação; promoções de vendas; } \\
\text { embalagens; patrocínio. }\end{array}$ \\
\hline & $\mathbf{I}$ & $\begin{array}{l}\text { Melhorar a qualidade nutricional } \\
\text { de todos os alimentos ofertados. }\end{array}$ & $\begin{array}{l}\text { Reformulação para reduzir sal e gorduras; eliminar } \\
\text { gorduras trans; reduzir a densidade energética dos } \\
\text { alimentos processados; limitar o tamanho de } \\
\text { porções. }\end{array}$ \\
\hline & $\mathbf{S}$ & $\begin{array}{l}\text { Estabelecer incentivos e regras } \\
\text { para criar um ambiente saudável } \\
\text { no comércio varejista e nos } \\
\text { serviços de alimentação. }\end{array}$ & $\begin{array}{l}\text { Incentivos aos estabelecimentos comerciais para } \\
\text { localizar em áreas carentes; restrições nos projetos } \\
\text { de planejamento de estabelecimentos de } \\
\text { alimentação; promoção nas lojas. }\end{array}$ \\
\hline $\begin{array}{l}\text { Sistema de } \\
\text { alimentação }\end{array}$ & $\mathbf{H}$ & $\begin{array}{l}\text { Aproveitar a cadeia de } \\
\text { abastecimento alimentar para, } \\
\text { através dela, desenvolver ações } \\
\text { em todos os seus setores para } \\
\text { assegurar adesão com a saúde. }\end{array}$ & $\begin{array}{l}\text { Incentivos à cadeia de abastecimento no que tange a } \\
\text { produção; contratos públicos com pequenas cadeias } \\
\text { de abastecimento; abordar a saúde em todas as } \\
\text { políticas; estruturas de governança com } \\
\text { envolvimento multissetorial. }\end{array}$ \\
\hline \multirow[t]{3}{*}{$\begin{array}{l}\text { Comunicaçã } \\
\text { o e mudança } \\
\text { de } \\
\text { comporta- } \\
\text { mento }\end{array}$} & $\mathbf{I}$ & $\begin{array}{l}\text { Informar as pessoas sobre } \\
\text { alimentação e nutrição para } \\
\text { sensibilização/conscientização } \\
\text { do público. }\end{array}$ & $\begin{array}{l}\text { Educação com orientações sobre diretrizes de } \\
\text { alimentação em meios de comunicação em massa e } \\
\text { marketing social; campanhas de informação à } \\
\text { comunidade e de informação ao público. }\end{array}$ \\
\hline & $\mathbf{N}$ & $\begin{array}{l}\text { Conselhos e recomendações } \\
\text { nutricionais } \\
\text { englobando os cuidados com a } \\
\text { saúde }\end{array}$ & $\begin{array}{l}\text { Aconselhamento de nutrição para indivíduos em } \\
\text { risco; aconselhamento e suporte por telefone; } \\
\text { diretrizes clínicas para profissionais de saúde sobre } \\
\text { intervenções eficazes para nutrição. }\end{array}$ \\
\hline & $\mathbf{G}$ & $\begin{array}{l}\text { Dar educação nutricional e } \\
\text { habilidades. }\end{array}$ & $\begin{array}{l}\text { Introduzir na educação curricular orientações sobre } \\
\text { nutrição, culinária e produção de alimentos; } \\
\text { programas de instrução em saúde. }\end{array}$ \\
\hline
\end{tabular}

Fonte: Adaptado de Roberto et al, 2015 30,31 
A segunda série temática destinada à obesidade, publicada em fevereiro/2015, pelo Journal The Lancet, ressalta que os fatores ambientais podem interferir na responsabilidade que as pessoas devem ter pela própria saúde. Os fatores ambientais atuam explorando as vulnerabilidades social, biológica, fisiológica e econômica das pessoas, destruindo pouco a pouco suas habilidades de exercer os próprios interesses. Esses fatores afetam as preferências e as demandas dos indivíduos que passam a optar por alimentos não saudáveis. Promovendo assim, um ciclo vicioso, que conduz cada vez mais à busca por alimentos inadequados e pouco saudáveis. No entanto, reforçam nas publicações que o ciclo pode ser quebrado por regulamentações e interesses do governo, da sociedade civil e da indústria ${ }^{30}$.

Exemplos de ações com caráter intervencionista em prol de uma alimentação saudável têm sido desenvolvidas ao redor do mundo. O México, por exemplo, instituiu uma taxação para bebidas açucaradas e outros alimentos considerados "junk foods", com objetivo de reduzir a obesidade e as doenças dentárias ${ }^{32}$. No Reino Unido, em 2013, duas empresas seguiram a proposta do governo e dotaram o esquema de rotulagem nutricional com informações dispostas na parte frontal das embalagens e 36 empresas de alimentos e de bebidas assinaram compromisso de redução de calorias ${ }^{33}$.

Outras iniciativas além das regulatórias também têm sido desenvolvidas, como é o caso da atitude de uma grande companhia que reduziu o preço de frutas, de verduras e de grãos integrais e negociou com as indústrias fornecedoras de alimentos industrializados para reduzirem a porcentagem de açúcar e de sódio dos produtos $^{34}$. No Brasil, a preocupação com o aumento expressivo das DCNTs e suas consequências ao SUS, levou o governo federal firmar acordos de cooperação com as entidades representativas da indústria de alimento com a finalidade de propor estratégias gradativas de redução, principalmente, de açúcares, sódio e gorduras saturadas e ácidos graxos trans em alimentos processados ${ }^{35}$.

\section{Rotulagem de alimentos: canal de comunicação e instrumento de promoção da saúde}

A rotulagem é um meio de comunicação tensionado por vários atores que competem por este espaço de diálogo, tendo em vista os mais variados interesses. Utilizada de forma responsável, a rotulagem pode ser um instrumento de PS no campo da saúde pública, uma vez que é capaz de fornecer informações que possibilitam o consumidor a realizar comparações entre os produtos e a fazer suas escolhas alimentares, exercendo sua autonomia decisória por alimentos mais saudáveis. A opção por alimentos mais saudáveis implica em melhorar os hábitos alimentares e optar por alimentos mais nutritivos, menos calóricos e com reduzidos teores de gordura, açúcar e sódio ${ }^{19,36}$.

O consumidor busca informações em relação aos alimentos que consome em várias fontes: conhecimento de parentes e de amigos, educação, mídia, publicidade e rotulagem, todos esses canais transmitem as mais variadas informações. Para que a rotulagem dos alimentos seja considerada instrumento de PS efetivo, capaz de garantir o acesso e a apropriação da informação, é fundamental incentivar a leitura e promover a revisão na regulamentação, conforme preconiza a estratégia eixo de Promoção da Saúde do Plano de Ações Estratégicas para o Enfrentamento das DCNTs 2011-2022 ${ }^{12}$. Os órgãos reguladores devem primar pelo o uso de informações mais simplificadas e que sejam fáceis e rápidas de serem interpretadas, visto que o consumidor não dispõe de tempo para se dedicar a informações detalhadas ${ }^{37,38}$.

$\mathrm{Na}$ literatura, são várias publicações que constatam, por meio de pesquisas científicas, que os consumidores brasileiros possuem consciência da importância da rotulagem dos alimentos, porém as mesmas publicações evidenciam os altos índices de rotulagem de alimentos em desacordo com legislação sanitária vigente e com informações ilegíveis, comprometendo a veracidade da informação ofertada. Ressaltam também o uso excessivo de informações técnicas, o que gera dificuldade no entendimento da mensagem; o excesso de propagandas; os baixos índices de consumidores que leem os rótulos dos alimentos no momento da compra; e a descrença na fidedignidade das informações disponíveis nos rótulos $28,36,39,40,41$.

A regulamentação da rotulagem de alimentos no Brasil vem se modernizando e, desde 1998, o processo de atualização conta com incorporações de informações recomendas pelo Codex Alimentarius e OMS, concernentes ao contexto da saúde pública com a atenção voltada para as DCNTs e para os hábitos alimentares. As atualizações também visam à harmonização da regulamentação nacional às normas do bloco econômico do Mercado Comum do Sul $(\text { Mercosul) })^{42}$.

Apesar das várias conquistas, o Brasil ainda tem um longo caminho a percorrer, para tornar a rotulagem dos alimentos um instrumento de informação e de promoção de escolhas alimentares saudáveis. O Instituto Brasileiro de Defesa do Consumidor ${ }^{43}$ (IDEC) lançou, em 2014, a publicação "Rotulagem de alimentos e doenças crônicas: percepção do consumidor no Brasil", trata-se de um estudo inédito sobre o comportamento, a percepção e o entendimento de mulheres brasileiras em relação à rotulagem de alimentos e a associação dessas características com as DCNTs. A pesquisa avaliou 807 mulheres, em 4 capitais brasileiras; em relação à rotulagem nutricional. Quando foi perguntado às mulheres se costumam ler os rótulos dos alimentos 
antes de comprar 51\% afirmaram que "às vezes leem", $27 \%$ disseram que "sempre leem" contra $21 \%$ que disseram que "nunca leem".

A proposta do "semáforo nutricional na parte frontal das embalagens" foi bem aceita por cerca $80 \%$ das entrevistadas. A ideia do semáforo segue um modelo da Agência Regulatória do Reino Unido que, por meio das cores, facilita o entendimento do consumidor: a cor verde é usada para nutrientes que aparecem em quantidades baixas, o amarelo para os que aparecem em quantidades medianas e a cor vermelha para os que aparecem em quantidades altas, ou ainda, indicariam alimentos ricos em sódio, em açúcares e em gorduras ${ }^{43}$.

Segundo 59\% das mulheres entrevistadas, as marcações com cores nos rótulos nutricionais (como no semáforo) estimulariam uma mudança em seu hábito de consumo de alimentos. Constatação que reforça que a informação disponibilizada de forma clara, de fácil entendimento e sem rebuscamentos de dizeres técnicos tende a influenciar o consumidor em suas escolhas alimentares por hábitos mais saudáveis ${ }^{43}$.

\section{O poder do marketing}

As indústrias com suas estratégias de marketing orientadas para o estímulo ao consumo e convencimento do consumidor fazem da rotulagem dos alimentos um espaço de divulgação, secundarizando informações fundamentais como lista de ingredientes e tabela nutricional. Segundo Marins ${ }^{44}$ chegam ao cúmulo, em muitos casos, de atribuir aos produtos alimentícios as mais diversas propriedades como se fossem "pílulas milagrosas".

Por meio de recursos de linguagem persuasivos, o marketing utiliza-se amplamente das mais diversas formas de comunicação mercadológica para convencer o público fiel aos padrões e às modas ditadas pela mídia, que para se ter acesso a uma alimentação adequada e saudável, é necessário investir em produtos $\operatorname{caros}^{45,46}$.

Entretanto, o Guia Alimentar para População Brasileira $^{16}$, revisado em 2014, ressalta que alimentação saudável não é sinônimo de alimentação de alto custo. Esse conceito é muitas vezes criado pelo preço elevado dos alimentos ultraprocessados "enriquecidos" com diversos nutrientes e vitaminas e vendidos como alimentos ideais para o público que quer emagrecer. $\mathrm{O}$ guia propõe que os alimentos in natura e minimamente processados sejam a base da alimentação. O alerta do guia é direcionado ao consumo dos alimentos ultraprocessados que vendem a imagem de serem "irresistíveis" e práticos, de baixo custo e de alta durabilidade, mas apresentam, normalmente, alta concentração de aditivos e de conservantes, alto valor calórico, quantidades elevadas de sódio, gordura, açúcar e pobres em fibras.

As políticas de saúde voltadas para limitar a publicidade enganosa e abusiva nos alimentos apresentam intensões elogiáveis, porém o cumprimento das propostas se esbarram nos conflitos de interesses que podem afetar o desenho e o curso de implementação das ações governamentais. Essas propostas mobilizam um montante expressivo de recursos públicos e envolvem interesses econômicos de larga escala. É preponderante o respaldo social na proposição de estratégias e de regulamentações que exijam que se cumpra o direito à informação, primando pela promoção e pela proteção da saúde ${ }^{39}$.

\section{Conclusão}

A rotulagem de alimentos é uma "vitrine" visada por diversos interesses. Conforme retrata a literatura científica nacional, a configuração atual da problemática da rotulagem de alimentos no Brasil pode ser ilustrada por uma conjuntura constituída por consumidores, que dizem reconhecer a relevância dos rótulos dos alimentos, mas na ocasião da compra dos alimentos leem e compreendem pouco as informações disponibilizadas nos rótulos. Essa realidade encontrase relacionada ao fato dos rótulos apresentarem informações muito técnicas e pouco claras.

Além disso, os rótulos são frequentemente alvo de estratégias de marketing usadas, muitas vezes, para confundir e enganar os consumidores. Diante desse cenário, evidencia-se a necessidade de se trabalhar ações efetivas de promoção da saúde, tendo como objetivo norteador a democratização da informação completa e verdadeira, na tentativa de empoderar o consumidor e proporcionar a transformação de seus comportamentos e hábitos, tornando-o cada vez mais exigente, participativo e executor de sua autonomia.

Muitas proposições de medidas sugeridas no campo da rotulagem dos alimentos carecem do empenho do Estado em legitimar políticas públicas que contribuam para uma transformação social em prol de uma melhor qualidade de vida. Na realidade, os caminhos são muitos, a disponibilização das informações é a peça central para a obtenção da melhor direção. Porém, existem alguns segmentos que lucram com a falta de conhecimento por parte do consumidor. A esses segmentos interessam cidadãos passivos e sem atitudes, mergulhados em um mundo de informações que promove uma desorientação ao invés de instrução. 


\section{Declaração de conflitos de interesses}

Os autores do artigo afirmam que não houve nenhuma situação de conflito de interesse, tais como propostas de financiamento, emissão de pareceres, promoções ou participação em comitês consultivos ou diretivos, entre outras, que pudessem influenciar no desenvolvimento do trabalho.

\section{Referências}

1 - BRASIL. Ministério da Saúde. Secretaria de Vigilância em Saúde. Política Nacional de Promoção da Saúde. Brasília: 2010. 60p. (Série B. Textos Básicos de Saúde). Disponível

<http://bvsms.saude.gov.br/bvs/publicacoes/

politica_nacional_promocao_saude_3ed.pdf $>$.

2 - FREEMAN, R.; MORAN, M. A Saúde na Europa. In: NEGRI B.; VIANA A.L.A., (Orgs.). O Sistema Único de Saúde em Dez Anos de Desafio. São Paulo: Sobravime, 2002. p. 45-64.

3 - BARATA, R. B. Epidemiologia social: Revista Brasileira de Epidemiologia, v.8, n.1, p. 7-17, 2005.

4 - BUSS, P. M. Promoção da saúde e qualidade de vida. Ciência \&Saúde Coletiva, v. 5, n. 1, p. 163-177, 2000.

5 - TAVARES, M. F. L; ZANCAN, L.; CARVALHO, A. I.; ROCHA, R. M. Promoção da saúde como política e a Política Nacional de Promoção da Saúde. In: GONDIM, R.; GRABOIS, V.; MENDES JUNIOR, W. V. (Orgs.). Qualificação dos Gestores do SUS. 2. ed. Rio de Janeiro: Fiocruz/ENSP/EAD; 2011, p. 297-310.

6 - BUSS, P. M. Uma introdução ao conceito de promoção da saúde. In: CZERESNIA, D.; FREITAS, C. M. de (Orgs.). Promoção da saúde: conceitos, reflexões, tendências. 2 ed. rev. ampl. Rio de Janeiro: Fiocruz, 2009, p. 15-38.

7 - ESCOREL, S. História das Políticas de Saúde no Brasil de 1964 a 1990: do golpe militar à reforma sanitária. In: GIOVANELLA, L.; ESCOREL, S.; LOBATO, L. V. C.; NORONHA, J. C. de; CARVALHO, A. I. de, (Orgs.). Políticas e Sistemas de Saúde no Brasil. 2 ed. rev. ampl. Rio de Janeiro: Fiocruz, 2012, p. 323-364.

8 - BRASIL. Ministério da Saúde. Secretaria de Políticas de Saúde. Projeto Promoção da Saúde. As Cartas da Promoção da Saúde. Brasília: 2002. 56 p. (Série B. Textos Básicos em Saúde). Disponível em: <http://bvsms.saude.gov.br/bvs/publicacoes/cartas_promoc ao.pdf $>$.

9 - ARPINI, L. S. B; ARPINI, A. F. Integração dos campos de saúde coletiva e alimentação e nutrição num contexto de promoção da saúde relacionado às doenças crônicas não transmissíveis. Demetra, v. 9, n. 2, p. 451-465, 2014.

10 - SCHMIDT, M. I.; DUNCAN, B. B.; AZEVEDOS, G.; MENEZES, A. M.; MONTEIRO, C. A.; BARRETO, S. M.; CHOR, D.; MENEZES, P. R.Chronic non-communicable diseases in Brazil: burden and current challenges. The Lancet, v. 377, n. 9781, p. 1949-1961, 2011.

11 - DUNCAN, B. B; CHOR, D.; AQUINO, E. M. L.; BENSENOR, I. M.; MILL, J. G.; SCHIMIDT, M. I.; LOTUFO, P. A.; VIGO, A.; BARRETO, S. M. Doenças Crônicas não Transmissíveis no Brasil: prioridade para enfrentamento e investigação. Revista de Saúde Pública, v. 46, Supl., p. 126-134, 2012.
12 - BRASIL. Ministério da Saúde. Secretaria de Vigilância em Saúde. Plano de ações estratégicas para enfrentamento das doenças crônicas não transmissíveis (DCNT) no Brasil 2011-2022. Brasília: 2011. 160 p. (Série B. Textos Básicos em Saúde). Disponível em: <http://bvsms.saude.gov.br/bvs/publicacoes/plano_acoes_e nfrent_dent_2011.pdf>

13 - BRASIL. Ministério da Saúde. Secretaria de Vigilância em Saúde. VIGITEL Brasil 2014: Vigilância de fatores de risco e proteção para doenças crônicas por inquérito telefônico. Brasília: 2015. 152 p. Disponível em: <http://bvsms.saude.gov.br/bvs/publicacoes/vigitel_brasil_ 2014.pdf $>$.

14 - MALTA, D. C.; JÚNIOR, J. B. S. Plano de Ações Estratégicas para o Enfrentamento das Doenças Crônicas Não Transmissíveis no Brasil após três anos de implantação, 2011-2013. Epidemiologia e Serviços de Saúde, v. 23, n. 3, p. 389-395, 2014.

15 - FEIJÓ, M. B.; FERNANDES, M. L.; SOUZA, P. S. Hábitos alimentares e sua relação com as doenças crônicas não transmissíveis. In: MARINS, B. R.; TANCREDI, R. C. P.; GEMAL, A.L. (Orgs.). Segurança alimentar no contexto da vigilância sanitária: reflexões e prática. Rio de Janeiro: EPSJV, 2014. p. 125-153.

16 - BRASIL. Ministério da Saúde. Secretaria de Atenção à Saúde. Departamento de Atenção Básica. Guia alimentar para a população brasileira. 2. ed. Brasília: 2014. 156 p. Disponível

<http://bvsms.saude.gov.br/bvs/publicacoes/guia_alimentar _populacao_brasileira_2ed.pdf.>.

17 - FONSECA, A. B.; SOUZA, T. S. N.; FROZI, D. S.; PEREIRA, R. A. Modernidade alimentar e consumo de alimentos: contribuições sócio antropológicas para a pesquisa em nutrição. Ciência \& Saúde Coletiva, v. 16, n. 9, p. 3853-3862, 2011.

18 - FERREIRA, J. S. G.; SILVA, Y.; MORAES, O. M. G.; TANCREDI, R. P. Marketing de alimentos industrializados destinados ao público infantil na perspectiva da rotulagem. Vigilância Sanitária em Debate: Sociedade, Ciência \& Tecnologia, v. 3, n. 2, p. 75-84, 2015.

19 - MARINS, R. M.; ARAUJO, I. S. de; JACOB, S. C. Vigilância Sanitária e direito à comunicação: a rotulagem de alimentos como espaço de cidadania. Vigilância Sanitária em Debate: Sociedade, Ciência \& Tecnologia, v. 2, n. 4, p. 86-95, 2014.

20 - UNESP. Tipos de revisão de literatura. Biblioteca Professor Paulo de Carvalho Matos. 2015.

21 - POBLACIÓN, D. A. Literatura cinzenta ou não convencional: um desafio a ser enfrentado. Ciência da Informação, v. 21, n. 3, 1992.

22 - BRASIL. Lei ${ }^{\circ} 11.346$ de 15 de setembro de 2006. Cria o Sistema Nacional de Segurança Alimentar e Nutricional SISAN com vistas em assegurar o direito humano à alimentação adequada e dá outras providências. Diário Oficial da União 2006; 18 set.

23 - LEÃO, M. (Org.). O direito humano à alimentação adequada e o sistema nacional de segurança alimentar e nutricional. Brasília: 2013. 263 p. Disponível em: <http://www.oda-alc.org/documentos/1374763097.pdf>. 
24 - BRASIL. Lei $\mathrm{n}^{\circ} 8.080$ de 19 de setembro de 1990. Dispõe sobre as condições para a promoção, proteção e recuperação da saúde, a organização e o funcionamento dos serviços correspondentes e dá outras providências. Diário Oficial da União 1990; 20 set.

25 - BRASIL. Lei no 8.078 de 11 de setembro de 1990. Dispõe sobre a proteção do consumidor, e dá outras providências. Diário Oficial da União 1990; 12 set.

26 - BRASIL. Ministério da Saúde. Secretaria de Atenção à Saúde. Departamento de Atenção Básica. Política Nacional de Alimentação e Nutrição.2.ed. rev. Brasília:2012. 84 p. (Série B. Textos Básicos em Saúde). Disponível em: <http://189.28.128.100/dab/docs/portaldab/publicacoes/pna n2011.pdf $>$.

27 - TANCREDI, R. C. P.; FERNANDES, M. L. Segurança alimentar: o poder público na aplicabilidade normativa. In: MARINS, B. R.; TANCREDI, R. C. P.; GEMAL, A. L. (Orgs.). Segurança alimentar no contexto da vigilância sanitária: reflexões e prática. Rio de Janeiro: EPSJV, 2014. p. 69-91.

28 - SOUZA, S. M. F. C.; LIMA, K. C.; MIRANDA, H. F.; CAVALCANTI, F. I. D. Utilização da informação nutricional de rótulos por consumidores de Natal, Brasil. Revista Panamericana de Salud Pública, v. 29, n. 5, p. 337-43, 2011.

29 -WORLD HEALTH ORGANIZATION (WHO). Global action plan for the prevention and control of noncommunicable diseases 2013-2020. Geneva: WHO; 2013. Disponível em http://apps.who.int/iris/bitstream/10665/94384/1/97892415 06236_eng.pdf?ua=1>.

30 - ROBERTO, C. A.; SWINBUM, B.; HAWKES, C.; TKHUANG, T.; COSTA, S. A.; ASHE, M.; ZWICKER, L.; CAWLEY, J. H.; BROWNELL, K. D. Patchy progress on obesity prevention: emerging examples, entrenched barriers, and new thinking. Lancet [periódico na Internet]. 2015Fev[acessado 2015 Mar 14] [cerca de 10 p.]. Disponível em: 〈http://dx.doi.org/10.1016/S0140-6736(14)61744-X〉.

31 - WORLD CANCER RESEARCH FUND (WCRF) International NOURISHING framework. Use economic tools to address food affordbility and purchase incentives. London: WCRF; 2014. Disponível em: < http://www.wcrf.org/int/policy/nourishing-framework>.

32 - BROWNELL, K. D.; FARLEY, T.; WILLETT, W.C.; POPKIN, B. M.; CHALOUPKA, F. J.; THOMPSON, J. W.; LUDWIG, D. S. The Public Health and Economic Benefits of Taxing Sugar-Sweetened Beverages. New England Journal of Medicine, v. 361, n. 16, p. 1599-1605, 2009.

33 - DEPARTMENT OF HEALTH UK. Public health responsibility deal. United Kingdom of Great Britain: Department of Health; 2012. Disponível em: <https://responsibilitydeal.dh.gov.uk/about/>.

$34-$ JEBB, S. A. The public health responsibility deal food network. Nutrition Bulletin [periódico na Internet]. 2012Nov[acessado 2015 Mar 14];37(4):[cerca de 4 p.]. Disponível

http://onlinelibrary.wiley.com/doi/10.1111/j.1467-

3010.2012.01992.x/abstract?

userIsAuthenticated $=$ false $\&$ deniedAccessCustomisedMessa ge=.>.
35 - MARTINS, A. P. B. (Org.). Redução de sódio em alimentos: uma análise dos acordos voluntários no Brasil. Instituto Brasileiro de Defesa do Consumidor. Cadernos Idec. São Paulo: 2014.90 p. (Série Alimentos). Disponível em:

<http://www.idec.org.br/uploads/publicacoes/publicacoes/c aderno-idec-sodio-alimentos.pdf >

36 - CAVADA, G. S.; PAIVA, F. F.; Helbig, E.; BORGES, L. R. Rotulagem nutricional: você sabe o que está comendo? Brazilian Journal of Food Technology, v. 18, spe, p. 84-88, 2012.

37 - CONSUMERS INTERNATIONAL. Etiquetado nutricional en los alimentos reenvasados. Consumers International; 2015 FEV. Disponível em: <http://es.consumersinternational.org/media/1549574/eswcrd-2015-informe-4-etiquetado-nutricional.pdf >

38 - HAWKES, C. Informação Nutricional e Alegações de Saúde: o cenário global das regulamentações/Organização Mundial de Saúde; tradução de Gladys Quevedo Camargo. - Brasília: Organização Pan-Americana da Saúde; Agência Nacional de Vigilância Sanitária, 2006. 116 p. Disponível em:

<http://www.anvisa.gov.br/alimentos/informacao_nutricion al_alegacoes_saude_cenaario_global_regulamentacoes.pdf $>$.

39 - BURLANDY, L.; ALEXANDRE, V. P.; GOMES, F. S.; CASTRO, I. R. R.; DIAS, P. C.; HENRIQUES, P.; CARVALHO, C. M. P.; CASTRO JÚNIOR, P. C. P. Políticas de promoção da saúde e potenciais conflitos de interesses que envolvem o setor privado comercial. Ciência \& Saúde Coletiva, v. 21, n. 6, p.1809-1818, 2016.

40- LOBANCO, C. M.; VEDOVATO, G. M.; CANO, C. B.; BASTOS, D. H. M. Fidedignidade de rótulos de alimentos comercializados no município de São Paulo, SP. Revista Saúde Pública; v. 43, n. 3, p. 499-505, 2009.

41 - BENDINO, N. I.; POPOLIM, W. D.; OLIVEIRA, C. R. A. Avaliação do conhecimento e dificuldades de consumidores frequentadores de supermercado convencional em relação à rotulagem de alimentos e informação nutricional. Journal of the Health Sciences Institute, v. 30, n. 3, p. 261-265, 2012

42 - FERNANDES, M. L.; MARINS, B. R. Rotulagem nutricional: ferramenta de informação para o consumidor. In: MARINS, B. R.; TANCREDI, R. C. P.; GEMAL, A. L.(Orgs.). Segurança alimentar no contexto da vigilância sanitária: reflexões e prática. Rio de Janeiro: EPSJV, 2014. p. 155-184.

43 - MARTINS, A. P. B.(Org.). Rotulagem de alimentos e doenças crônicas: percepção do consumidor no Brasil. Instituto Brasileiro de Defesa do Consumidor. Cadernos Idec. São Paulo: 2014. 85 p. (Série Alimentos). Disponível em:

<http://www.idec.org.br/uploads/publicacoes/publicacoes/r otulagem-de-alimentos-e-doencas-cronicas.pdf $>$.

44 - MARINS, R. M.; ARAUJO, I. S. de; JACOB, S. C. A propaganda de alimentos: orientação, ou apenas estímulo de consumo? Ciência\& Saúde Coletiva, v. 16, n. 9, p. 38733882, 2011.

45 - MARTINS, A. P. B. (Org.). Publicidade de alimentos não saudáveis: os entraves e as perspectivas de regulação no Brasil. Instituto Brasileiro de Defesa do Consumidor. Cadernos Idec. São Paulo: 2014. 150 p. (Série Alimentos). Disponível em: <http://www.idec.org.br/pdf/publicidadealimentos-nao-saudaveis.pdf $>>$ 
46 -DEPARTAMENTO DO AGRONEGÓCIO. Secretaria de Agricultura e Abastecimento. Agência Paulista de Tecnologia dos Agronegócios. Instituto de Tecnologia de Alimentos. Federação das Indústrias do Estado de São Paulo. Brasil Food Trends 2020. São Paulo: 2010.176 p. Disponível em: <http://www.brasilfoodtrends.com.br/brasil_food_trends/fil es/publication.pdf $>$. 